\title{
Well-Leg Compartment Syndrome after Fracture Fixation in Hemilithotomy Position: Case Report of a Preventable Condition
}

\author{
Sanjay Meena Vivek Trikha Pramod Saini Nishikant Kumar Subhash KR \\ Department of Orthopaedics, All India Institute of Medical Sciences, New Delhi, India
}

\section{Key Words}

Fracture $\cdot$ Shaft femur $\cdot$ Safety $\cdot$ Compartment syndrome . Hemilithotomy

\begin{abstract}
Objective: To report a case of subtrochanteric femur fracture that led to intraoperative compartment syndrome in the well leg. Clinical Presentation and Intervention: A 28-yearold obese male who presented with a comminuted subtrochanteric fracture underwent a prolonged open reduction and internal fixation using dynamic condylar screw. In the postoperative period, after the effect of epidural analgesia had worn off, the patient complained of severe pain and swelling of the well leg. A diagnosis of well-leg compartment syndrome was made and urgent two-incision fasciotomy was performed. Conclusion: Obesity and prolonged surgery could have caused the acute compartment syndrome of the well leg in this patient.

(c) 2013 S. Karger AG, Basel
\end{abstract}

\section{Introduction}

The fracture table is the most frequently used table in orthopaedic surgery for closed or open reduction of fractures around the hip and femoral shaft. This table makes fracture reduction easier and one can conveniently use an image intensifier [1]. Frequently, the patient is in hemilithotomy position on this table, which sometimes leads to unexpected complications. One such complication is well-leg compartment syndrome [1]. Compartment syndrome of the leg as a complication of the lithotomy position has been described in general surgery, urologic surgery, and gynaecological procedures, particularly following prolonged surgery [2]. Only a few reports exist in the literature which describe this complication as a result of positioning on the fracture table [3]. Leg compartment syndrome is a severe complication and has the potential to cause permanent neuromuscular dysfunction. Here, we report a case of well-leg compartment syndrome after prolonged surgery for subtrochanteric fracture in hemilithotomy position on the fracture table under general anaesthesia combined with epidural analgesia.

\section{Case Report}

A 110-kg 28-year-old male was admitted to the Emergency Department for subtrochanteric fracture of the right thigh following a road traffic accident. Besides the injured thigh, there was no complaint of pain at any other site. There was no associated injury and any other comorbid conditions. The patient was obese with a body mass index of 37 and no other comorbidities. He had no history of veno-occlusive disease, and all the preoperative laboratory evaluations were normal. Antegrade interlocking nailing was planned as a treatment strategy. He was taken into the operating theatre within $48 \mathrm{~h}$ of the trauma after adequate resuscitation. The surgery

\begin{tabular}{ll}
\hline KARGER & $\begin{array}{l}\text { (c) 2013 S. Karger AG, Basel } \\
\text { 1011-7571/13/0233-0275 } \$ 38.00 / 0 \quad \text { Karger } \\
\text { Open access }\end{array}$ \\
$\begin{array}{l}\text { E-Mail karger@karger.com } \\
\text { www.karger.com/mpp }\end{array}$ & $\begin{array}{l}\text { This is an Open Access article licensed under the terms of the } \\
\text { Creative Commons Attribution-NonCommercial 3.0 Un- } \\
\text { ported license (CC BY-NC) (www.karger.com/OA-license), } \\
\text { applicable to the online version of the article only. Distribu- } \\
\text { tion permitted for non-commercial purposes only. }\end{array}$
\end{tabular}

Sanjay Meena

Department of Orthopaedics

All India Institute of Medical Sciences

New Delhi 110029 (India)

E-Mail sanjaymeena@ hotmail.com 
was carried out under general anaesthesia, with epidural analgesia. The patient was positioned on a fracture table. The well leg was placed in hemilithotomy position in $70^{\circ}$ flexion and $40^{\circ}$ abduction, and it was placed on a leg holder. The patient was maintained in this position throughout the procedure. Following closed reduction of the fracture, nailing was attempted. But the failure to obtain acceptable reduction initially increased the surgical time; the intraoperative plan was changed and fixation with a dynamic condylar screw (DCS) was performed (fig. 1). The total surgical time was $2 \mathrm{~h}$ and $30 \mathrm{~min}$. There was $650 \mathrm{ml}$ of blood loss and 1 unit of whole blood was transfused intraoperatively. The patient's arterial blood pressure was maintained by the anaesthetists at $94 / 60 \mathrm{~mm} \mathrm{Hg}$ or above throughout the procedure as a preventive measure to reduce bleeding at the operative site. The intraoperative traction was released after $2 \mathrm{~h}$ for $5 \mathrm{~min}$. When the procedure was nearing completion, a dose of epidural analgesia was given to relieve the patient of any possible postoperative pain. The patient was shifted to the ward after the completion of surgery.

In the postoperative rounds, the distal pulses of the operated extremity were palpable and any neural deficit could not be assessed as the patient was under the effect of epidural analgesia. The well leg was not examined by the surgeon and the nurse. Four hours after the end of surgery, the patient complained of severe pain in the well leg. A tense and firm swelling was found and stretch pain was present (fig. 2). On physical examination, there was paraesthesia on the lateral aspect of the foot. A diagnosis of well-leg compartment syndrome was made. An urgent radiograph of the well leg was taken to exclude any bone injury which might have been missed. The radiographs revealed no bone injury, and the patient was treated with an immediate fasciotomy. A doubleincision fasciotomy was performed. Vacuum-assisted closure suction was applied over the fasciotomy wound (fig. 3). His wounds healed without difficulty and he regained normal strength and sensation in the lower extremity. The patient was discharged on the 20th postoperative day. The fracture united both clinically and radiologically at the 12th week. At the last follow-up at the end of 1 year, the patient had resumed his occupation.

\section{Discussion}

In the index case, prolonged surgery of a comminuted subtrochanteric fracture on a fracture table led to the development of compartment syndrome of the well leg.

In orthopaedic surgery, the hemilithotomy position is frequently used when a hip or femur fracture is being operated on a fracture table [4]. This position immediately increases calf compartment pressures (direct compression theory) and significantly decreases mean diastolic blood pressure (DBP) in the ankle (vascular insufficiency theory). The combination of both pathophysiologic events results in local ischaemia, tissue oedema and, ultimately, acute compartment syndrome [1]. In our patient, the combined effect of increased intramuscular pressure, due to external compression from the calf support, and decreased perfusion pressure, due to the elevated position,



Fig. 1. Postoperative radiograph showing fracture fixation with a DCS.

may have caused a significant decrease in difference between DBP and intramuscular pressure, which may have contributed to the development of this complication.

Due to the complicated fracture patterns, sometimes, these procedures may be prolonged. In the present scenario, intramedullary nailing is considered the gold standard for subtrochanteric fracture [5]. However, insertion of nails led to unacceptable varus position and abduction of the proximal fragment. Due to this, the fracture was fixed with a DCS. Obtaining the optimal vector from the entry point on a fracture table can be particularly difficult in obese patients because of the size of the torso as well as an inability to laterally flex the trunk on the opposite side of the fracture and to adduct the ipsilateral leg. Misjudging the starting point can lead to significant varus or valgus malalignment of the proximal femur in up to $23 \%$ of cases $[6,7]$. Prolonged surgery combined with a high body mass index was a predisposing factor for compartment syndrome. 


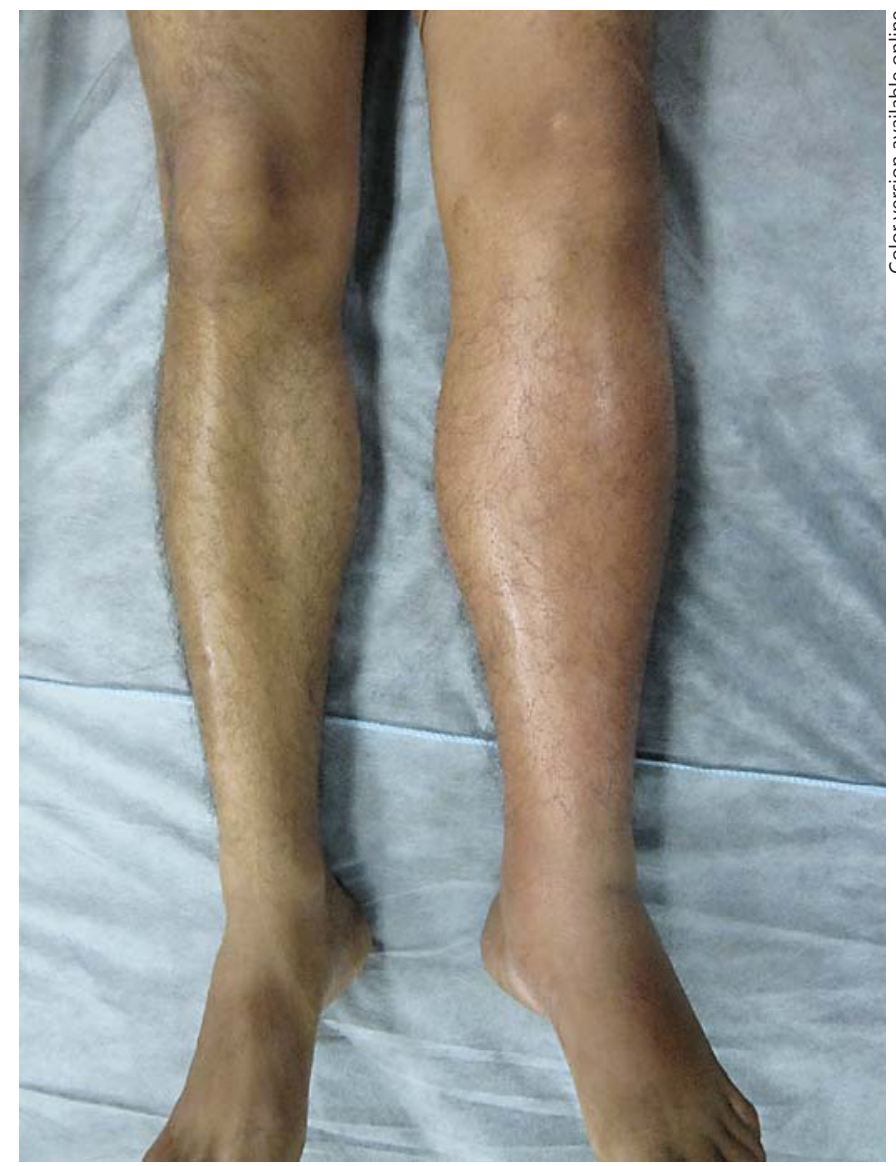

Fig. 2. Clinical picture of the leg showing massive swelling compared to the other leg.

The diagnosis of compartment syndrome is usually made clinically with patients complaining of paraesthesia, pain out of proportion to injury, pain on passive stretching, and tight calves. In advanced stages, peripheral pulses are absent $[8,9]$. Epidural analgesia may have reduced the classic symptoms of compartment syndrome in our case. This led to a delay in diagnosis causing an impending compartment syndrome progressing into a full-blown compartment syndrome. This has been reported as a contributing cause for delay in the diagnosis of well-leg compartment syndrome [10]. However, early diagnosis of compartment syndrome has also been made in patients despite having epidural anaesthesia. Therefore, clinicians' awareness of their patients' risk factors and a high index of suspicion are important during patient assessment. This patient was kept in systemic hypotension by the anaesthetist to prevent bleeding at the surgical site. This may have led to loss of driving pressure to the extremity, which was augmented by elevation of the

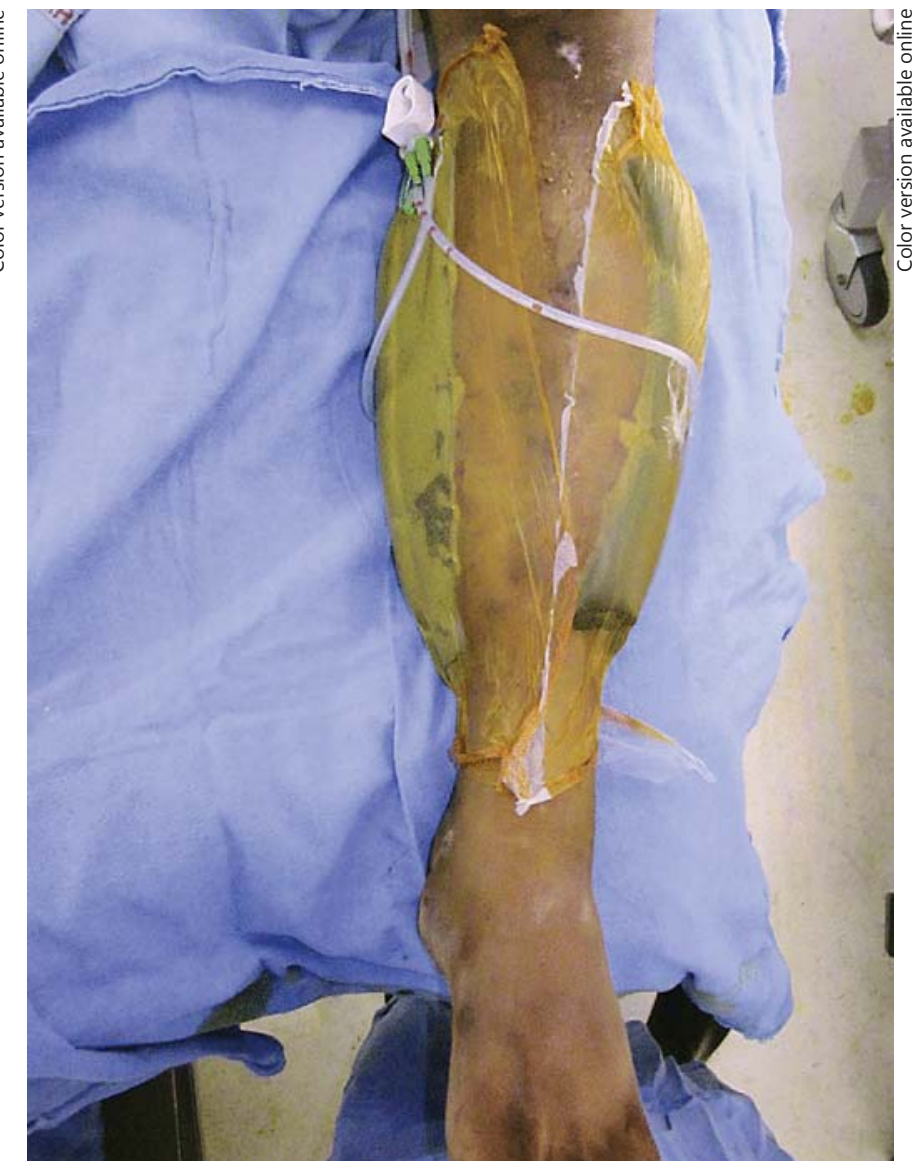

Fig. 3. Vacuum-assisted closure dressing applied after fasciotomy.

extremity, and compression of the extremity by wrappings that were too tight.

It is important that we recognize the risks and carry out necessary steps to prevent patients from developing this preventable complication. One of the important steps in this direction is keeping the calf free and using heel support instead. Leaving the calf free increases the difference between DBP and intramuscular pressure and may decrease the risk of acute compartment syndrome in obese patients. This may also lead to compartment syndrome, as the foot is in a dependent position. In such patients, fracture fixation can be done with both legs in extension. If one is to use the leg holder, then frequent repositioning of the well leg must be done.

To avoid such preventable complications we recommend that (1) blood pressure should not be significantly reduced; (2) the well-leg holder should be avoided whenever possible and leg position should be kept at heart level, and (3) perioperative monitoring of the patient is essential. 


\section{Conclusion}

This case showed that comminuted subtrochanteric fracture in this obese patient, who was operated in hemilithotomy position, led to compartment syn- drome. This complication appears to be widely unrecognized and more awareness by surgeons, anaesthetists, the recovery room team, nurses, etc. is required for early diagnosis and prevention of this morbid condition.

\section{References}

$>1$ Flierl MA, Stahel PF, Hak DJ, et al: Traction table-related complications in orthopaedic surgery. J Am Acad Orthop Surg 2010;18: 668-675.

-2 Karmaniolou I, Staikou C: Compartment syndrome as a complication of the lithotomy position. West Indian Med J 2010;59:698701.

3 Noordin S, Allana S, Wajid: Well leg compartment syndrome: the debit side of hemilithotomy position. J Ayub Med Coll Abbottabad 2009;21:166-168.
-4 Christodoulou M, Garofalo R, Echeverri S, et al: Hemilithotomy position for intramedullary nailing of the femur and compartment syndrome of the healthy leg. Swiss Surg 2002; 8:193-196.

-5 Li F, Sang W, Wang Q, et al: Subtrochanteric fracture treatment: a retrospective study of 46 patients. Med Princ Pract 2011;20:519-524.

6 Ostrum RF, Marcantonio A, Marburger R: A critical analysis of the eccentric starting point for trochanteric intramedullary femoral nailing. J Orthop Trauma 2005;19:681-686.

7 Starr AJ, Hay MT, Reinert CM, et al: Cephalomedullary nails in the treatment of high-energy proximal femur fractures in young patients: a prospective, randomized comparison of trochanteric versus piriformis fossa entry portal. J Orthop Trauma 2006;20:240-246.
8 Pearse MF, Harry L, Nanchahal J: Acute compartment syndrome of the leg. BMJ 2002;14: 325557-325558.

$>9$ Shadgan B, Menon M, Sanders D, et al: Current thinking about acute compartment syndrome of the lower extremity. Can J Surg 2010;53:329-334.

10 Simms MS, Terry TR: Well leg compartment syndrome after pelvic and perineal surgery in the lithotomy position. Postgrad Med J 2005; 81:534-536. 